\title{
Synthesis and Characterization of Graphene Thin Films by Chemical Reduction of Exfoliated and Intercalated Graphite Oxide
}

\author{
F. T. Thema, ${ }^{1}$ M. J. Moloto, ${ }^{1}$ E. D. Dikio, ${ }^{1}$ N. N. Nyangiwe, ${ }^{2,3}$ L. Kotsedi, ${ }^{3}$ \\ M. Maaza, ${ }^{3}$ and M. Khenfouch ${ }^{3,4}$ \\ ${ }^{1}$ Department of Chemistry, Vaal University of Technology, Vanderbijlpark, South Africa \\ ${ }^{2}$ Department of Physics, University of Western Cape, Bellville, South Africa \\ ${ }^{3}$ MRG Nanoscience Laboratories, iThemba Labs, Somerset West, South Africa \\ ${ }^{4}$ Group of Polymers and Nanomaterials, Laboratory of Solid State Physics, Faculty of Sciences Dhar El Mahraz, \\ Sidi Mohamed Ben Abdellah, University Fez, Morocco
}

Correspondence should be addressed to E. D. Dikio; ezekield@vut.ac.za

Received 22 April 2012; Accepted 29 May 2012

Academic Editor: Veysel T. Yilmaz

Copyright (C) 2013 F. T. Thema et al. This is an open access article distributed under the Creative Commons Attribution License, which permits unrestricted use, distribution, and reproduction in any medium, provided the original work is properly cited.

Commercial flakes of graphite were prepared into functionalized graphene oxide (GO) by chemical treatment. After the exfoliation and intercalation of graphene into functionalized graphene oxide that formed stable colloidal dispersion in polar aprotic solvent, the reduction process was undertaken by continuous stirring with hydrazine hydrate. The reduced material was characterized by X-ray diffraction (XRD), attenuated total reflectance (ATR) FT-IR, ultraviolet visible (UV-vis), atomic force microscopy (AFM) and Raman spectroscopy which confirm the oxidation of graphite and reduction of graphene oxide into graphene sheet.

\section{Introduction}

Graphene is a single two-dimensional carbon sheet with the same structure as individual layers of graphite packed into a hexagonal pattern. As a one atom-thick planar sheet of $s p^{2}$-bonded carbon atom, graphene has received much attention in the recent years in materials science due to unusual properties, such as a half-integer quantum hall effect and ballistic and extraordinary electron transport [1]. Precisely, grapheme-based assemblies are also gaining attention because of their potential in designing electronic, sensing, and energy conversion devices [2-6]. Graphene oxide (GO) synthesized from chemical oxidation of graphite provides a simple and convenient method to obtain exfoliated, twodimensional carbon sheets [7]. Graphene nanoplatelets can also be used in many applications, given the excellent inplane mechanical, structural, thermal, and electrical properties of graphite [8]. These excellent properties may be relevant at nanoscale if graphite can be exfoliated into thin nanoplatelets and even down to the single graphene sheet level [9].

Graphite nanoplatelets have often been made from expanded graphite, which in turn was produced from graphite intercalation compounds by rapid evaporation of the intercalant at elevated temperatures [10]. However, this simple method has been applied on a large scale to commercially available sulphuric acid-intercalated graphite; it never resulted in complete exfoliation of graphite to the level of individual graphene sheets [10]. The extent of thermal expansion (and therefore the platelets thickness) is dependent on the type of graphite used and the intercalation procedure $[11,12]$.

Oxidation diminishes graphene's excellent conducting properties, so reduction of GO is desirable in order to partially restore its $s p^{2}$ network [13]. Reduced graphene oxide (RGO) can be produced through chemical [13-15], sonolytic [16], microwave [17, 18], photo thermal [19, 20], photo catalytic [21-24], and electrochemical methods [25, 
26]. Graphene oxide is a hydrophilic derivative of graphene to which biological micromolecules readily attach. GO has properties superior to those of amorphous carbon films commonly used in electron microscopy [27]. However, though hydrophobic, graphene can be functionalized using chemical processes, thereby producing hydrophilic substrates to which molecules can readily attach.

Chemical reagents are critical to the reduction of GO, no matter in the solid phase or liquid state $[28,29]$. It is therefore critical to choose the method of synthesizing graphene taking into account its intended ultimate application. The introduction of chemical reagents is a significant disadvantage because the intrinsic response of graphene to trace analyte may be masked by the signals caused by impurities [27]. In this study, we present the synthesis and characterization of graphene thin films by chemical reduction of exfoliated and intercalated graphite oxide. Graphene oxide and reduced graphene oxide obtained were characterized by XRD, FT-IR, UV-vis AFM, and Raman spectroscopy.

\section{Experimental}

2.1. Materials. Sulphuric acid, hydrochloric acid, and hydrogen peroxide potassium permanganate used in this study were purchased from Sigma-Aldrich South Africa. Flake graphite powder and hydrazine hydrate were imported from Germany. Filter paper qualitative advantec $90 \mathrm{~mm}$ was bought from Toyo Roshi Kaisha Ltd. in Japan. Vacuum pump VDE $0530 / 72 \mathrm{~B} / \mathrm{IP} 44$ at $220 \mathrm{~V}, 0.75 \mathrm{Kw}, 1350 \mathrm{l} / \mathrm{min} 50 \mathrm{~Hz}$, $\mathrm{CB}=32 \mathrm{microfarad} / 400 \mathrm{~V}$ was obtained from vacuum pump South Africa.

2.2. Synthesis of Graphene Oxide (GO) and Reduced Grapheme $(R G O)$. Graphite was subjected to an oxidative treatment with potassium permanganate $\left(\mathrm{KMnO}_{4}\right)$ in concentrated sulphuric acid $\left(\mathrm{H}_{2} \mathrm{SO}_{4}\right)$ [30]. Natural flake graphite powder $(2.0 \mathrm{~g})$ was weighed and placed in a round bottom flask, $46 \mathrm{~mL}$ of concentrated sulphuric acid was added and the mixture cooled in an ice bath, and $6.0 \mathrm{~g}$ of potassium permanganate $\left(\mathrm{KMnO}_{4}\right)$ was gradually added over a period of $30 \mathrm{~min}$ with continuous stirring. The mixture was stirred at $35^{\circ} \mathrm{C}$ for 2 hours, then $92 \mathrm{~mL}$ of distilled water was slowly added to the mixture, and the temperature was maintained below $100^{\circ} \mathrm{C}$ for $15 \mathrm{~min}$. Finally, $280 \mathrm{~mL}$ of $30 \%$ hydrogen peroxide $\left(\mathrm{H}_{2} \mathrm{O}_{2}\right)$ solution was added to the mixture. The product was finally filtered with $500 \mathrm{~mL}$ of $10 \%$ hydrochloric acid $(\mathrm{HCl})$ solution to remove metal ions and then thoroughly washed with distilled water. Brown pasty material of GO was obtained. GO $(3.0 \mathrm{~g})$ was weighed to make colloidal dispersion in distilled water with continuous stirring in a microwave oven at a temperature of $35^{\circ} \mathrm{C}$. A solution of hydrazine hydrate $\left(\mathrm{H}_{2} \mathrm{O}_{4}\right)$ that weighed $10 \%$ of the GO dispersed in water was added as a reducing agent and stirred for $3 \mathrm{hrs}$. After this, the filtrate turned from brown to black and was filtered to obtain a black pasty material of grapheme [30].

2.3. Sample Preparation. Sonicated small amounts of colloidal dispersions of GO and RGO were dropped on a silica oxide thin glass substrates and left to dry overnight at room temperature. The silicon oxide substrates were cleaned by exposing the substrates in acetone and then sonicated for $5 \mathrm{~min}$ and left to air-dry.

2.4. Characterization. Attenuated total reflectance (ATR) Fourier transform infrared (FT-IR) spectra were recorded on a Perkin Elmer Spectrum 100 spectrometer in the 4000-500 region. Powder X-ray diffraction (XRD) spectroscopy was carried on a Brucker-D 8 advance, GER X-ray diffractometer using $\mathrm{Cu} \mathrm{K} \alpha$ irradiation (wavelength $=1.5406 \mathrm{~A}$ ). The operating voltage and current were $40 \mathrm{kV}$ and $300 \mathrm{~mA}$, respectively. The thickness and morphology of the as-prepared samples were determined by atomic force microscopy (Nanoman V AFM). The ultraviolet visible (CE 2021, 2000 series) was also used to further confirm the oxidation and reduction of graphite and graphene oxide. Magnified optical microscope M-service 470 majmf with 2000 magnification was used. The Raman spectra were obtained by a Raman spectroscope, Jobin-Yvon HR800 UV-VIS-NIR Raman spectrometer equipped with an Olympus BX 40 attachment. The excitation wavelength was $514.5 \mathrm{~nm}$ with an energy setting of $1.2 \mathrm{mV}$ from a coherent Innova model 308 argon-ion laser. The Raman spectra were collected by means of back scattering geometry with an acquisition time of 50 seconds.

\section{Results and Discussion}

The treatment of graphite with potassium permanganate and sulphuric acid produced brownish graphene oxide (GO) (Figure $1(\mathrm{a})$ ). The GO readily forms stable colloidal suspensions of thin sheets in water $[31,32]$. After ultrasonic treatment, the exfoliation process brings about stable dispersions of very thin graphene oxide $[33,34]$. Addition of hydrazine hydrate as a reducing agent enables the graphene oxide sheets that are homogenously dispersed in water to turn from brownish to black, (Figure 1(b)) conforming the reduction of graphene oxide to graphene with sheets that aggregate and ultimately precipitate [33].

X-ray diffraction of graphene oxide and reduced graphene oxide synthesized by chemical reduction of exfoliated and intercalated graphite oxide is presented in Figure 2. The spectra in Figures 2(a) and 2(b) show two peaks corresponding to graphene oxide and graphene. The strong peak at $2 \theta=11.6^{\circ}$ corresponds to an interlayer spacing of about $0.76 \mathrm{~nm}$, indicating the presence of oxygen functional group, which facilitated the hydration and exfoliation of graphene sheet in aqueous media. After chemical reduction, the hydrophilicity of water-dispersed GO sheet gradually decreased, leading to an irreversible agglomeration of reduced graphene oxide (RGO) sheet. The broad peak at $2 \theta=25.8^{\circ}$ indicates a random pucking of graphene sheets in the RGO. This peak is corresponding to 002 plane of graphite with interlayer spacing of $0.34 \mathrm{~nm}$ which is due to the removal of oxygen atoms that got into the graphite gallery during the intercalation process. This confirms the reduction process of graphene oxide to graphene. 


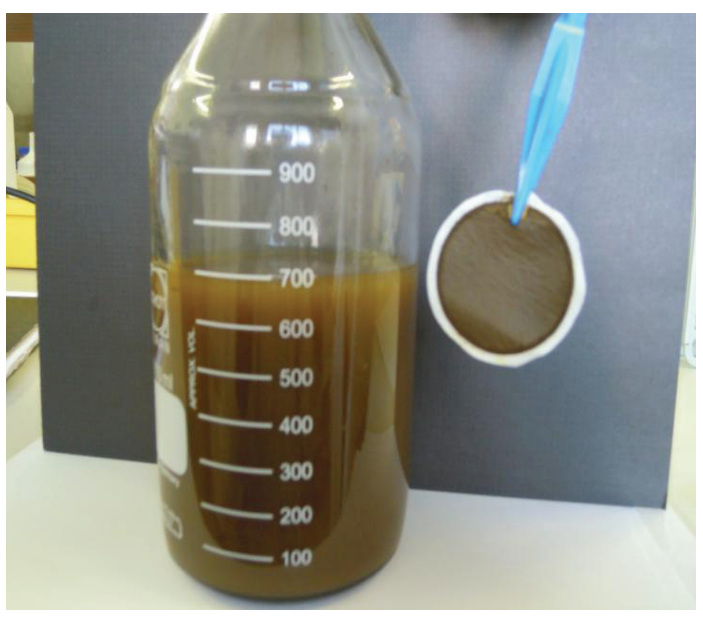

(a)

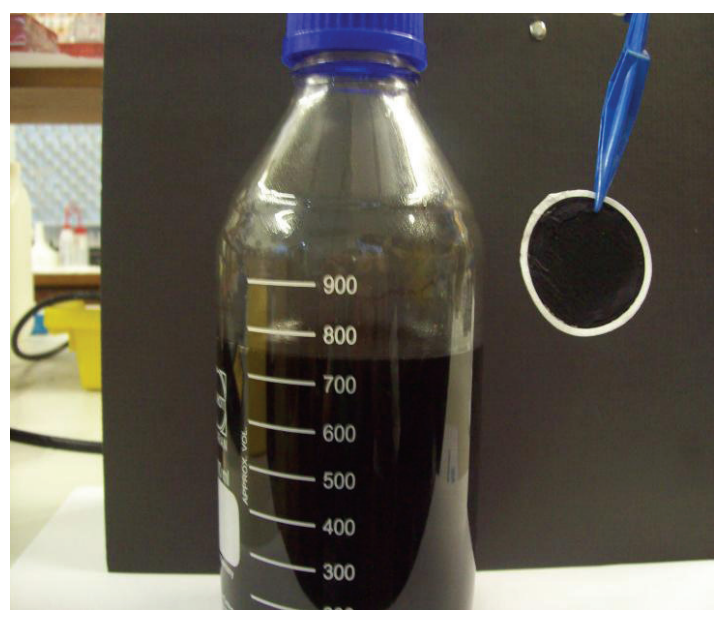

(b)

FIGURE 1: (a) Brownish graphene oxide and (b) blackish reduced graphene oxide.

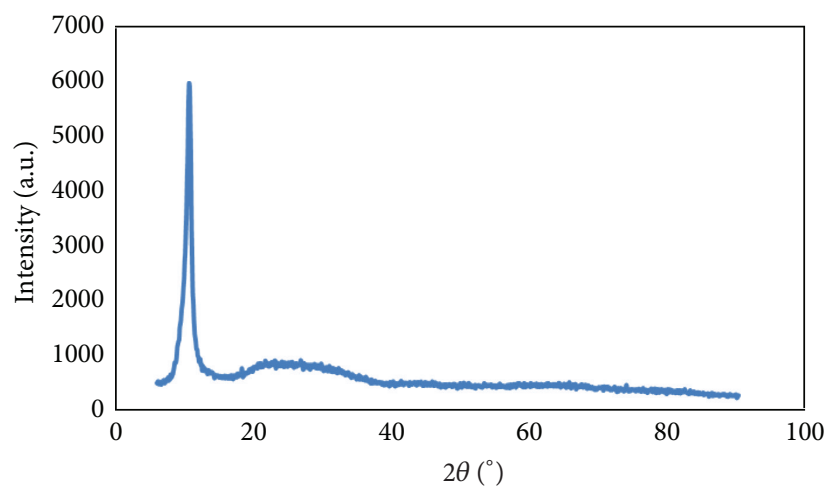

(a)

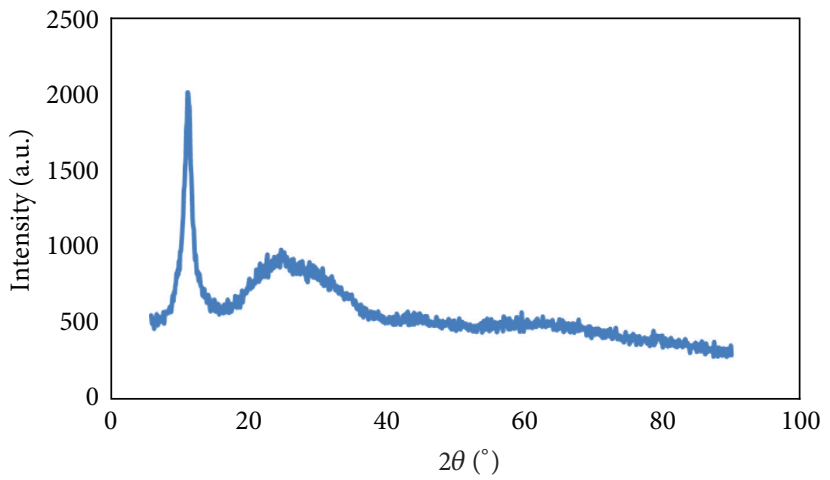

(b)

FIGURE 2: XRD diffractogram of (a) graphene oxide and (b) reduced graphene oxide.

Fourier transform infrared (FTIR), attenuated total reflectance (ATR) spectrum of graphene oxide and reduced graphene oxide are presented in Figure 3. The spectrum shows a peak of reduced graphene oxide representing $\mathrm{O}-\mathrm{H}$ stretching vibrations observed at $3400 \mathrm{~cm}^{-1}$ which was significantly reduced due to deoxygenation. The $\mathrm{C}=\mathrm{O}$ at $1720 \mathrm{~cm}^{-1}$ in this spectrum is due to the mechanism of exfoliation mainly because of the expansion of $\mathrm{CO}_{2}$ evolved into the interstices between the graphene sheets during rapid heating, and the $\mathrm{C}-\mathrm{O}$ stretching vibrations observed at $1060 \mathrm{~cm}^{-1}$ are due to the remaining carbonyl groups after the reduction process. The mechanism of exfoliation is mainly the peeling of graphitic structure to pave the way for the entering of oxygen during oxidation process. The peaks observed at 1220 to $1060 \mathrm{~cm}^{-1}$ are stretching vibrations on the graphene oxide indicating skeletal vibrations from unoxidised graphitic domain. So, the ATR spectra indicate that the bulk of the oxygen-containing functional groups has been removed from graphene oxide. This further confirms the reduction of graphene oxide by chemical reduction.
Figure 4 shows the ultraviolet-visible spectra of reduced graphene oxide and graphene oxide. The spectrum of graphene oxide has an absorption peak at $230 \mathrm{~nm}$ which is shifted to $270 \mathrm{~nm}$ in graphene. This is a red shift which is due to the electronic configuration in graphene in the reduction of graphene oxide. The absorption peak at $230 \mathrm{~nm}$ is attributed to $\pi-\pi^{*}$ transition of aromatic $\mathrm{C}-\mathrm{C}$ ring. The UV spectra of reduced grapheme oxide on the other hand show the red shift at $270 \mathrm{~nm}$. This absorption peak is attributed to $n-\pi^{*}$ transition of C-O bonds now embedded by exfoliation and intercalation on the graphene.

The level of exfoliation was evaluated by atomic force microscopy (AFM) as presented in Figures 5(a) and 5(b). The AFM images show a three-dimensional AFM topography of graphene oxide and reduced grapheme, respectively. The GO sheets are expected to be thicker due to the presence of covalently bonded oxygen and the displacement of $s p^{3}$ hybridized carbon atoms slightly above and below the original graphene plane. The height difference between rows is $1 \mathrm{~nm}$ in GO and $1.2 \mathrm{~nm}$ in RGO indicating a single graphene oxide sheet 


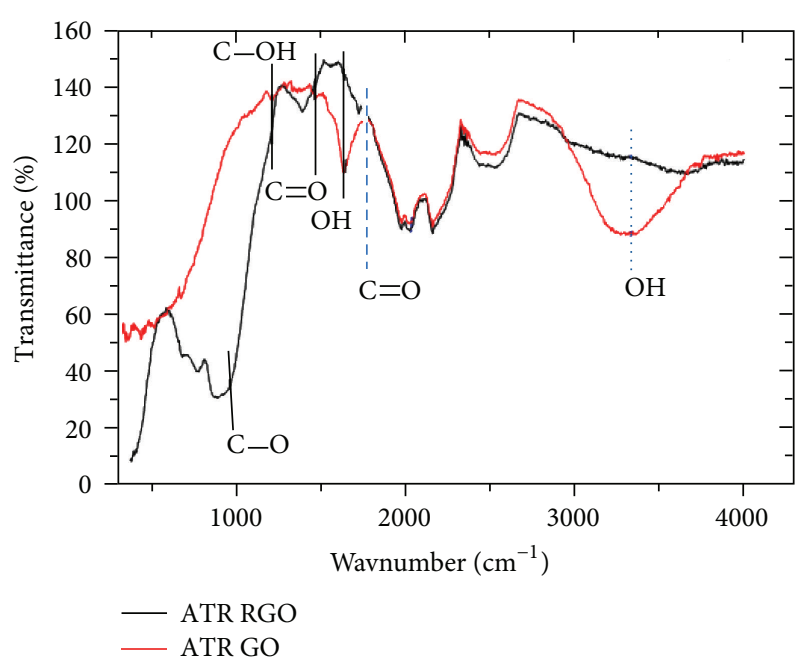

FIGURE 3: FT-IT (ATR) spectra of graphene oxide and reduced graphene oxide.

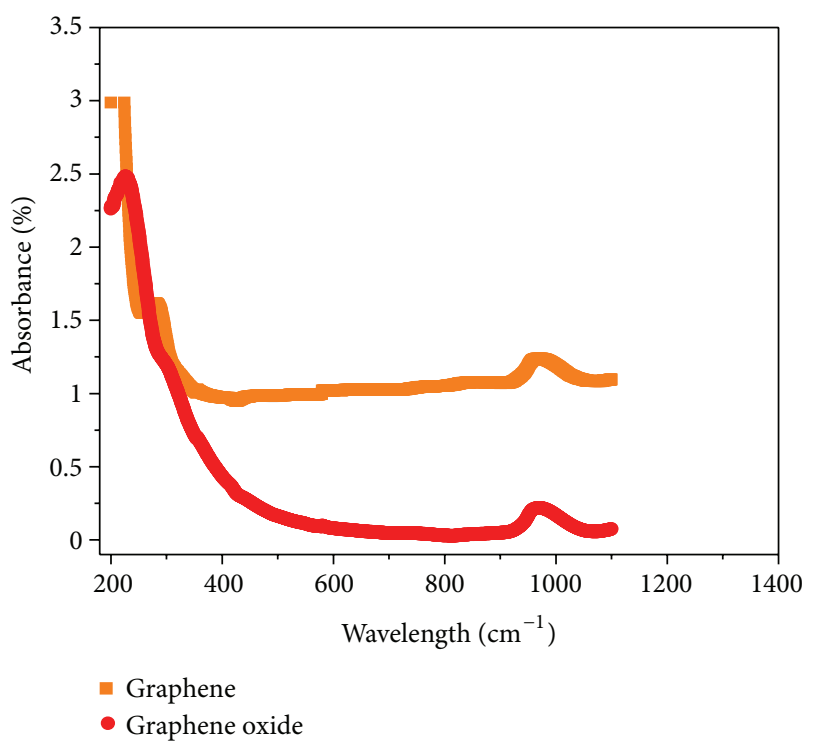

FIGURE 4: UV-vis spectra of graphene and graphene oxide.

due to intercalating of oxygen into the graphite gallery. The results reveal graphene oxide and reduced graphene oxide were obtained in the synthesis.

The Raman spectrum is presented by Figures 6(a) and 6(b). It is well known that Raman scattering is very sensitive to the microstructure of nanocrystalline materials. Figure 6(a) shows the Raman spectra of graphene oxide, while Figure 6(b) shows the Raman spectra of reduced graphene oxide. A comparison of the spectra of graphene oxide with that of reduced graphene oxide shows that the D and G bands of graphene which are observed at 1355 and $1605 \mathrm{~cm}^{-1}$ shifted to 1340 and $1586 \mathrm{~cm}^{-1}$, respectively. Simultaneously, relative intensity of $D / G$ was increased after hydrothermal reaction, which is confirmed by Lambert et al. [29] and Stankovich et al. [10]. This further confirms that graphene oxide was

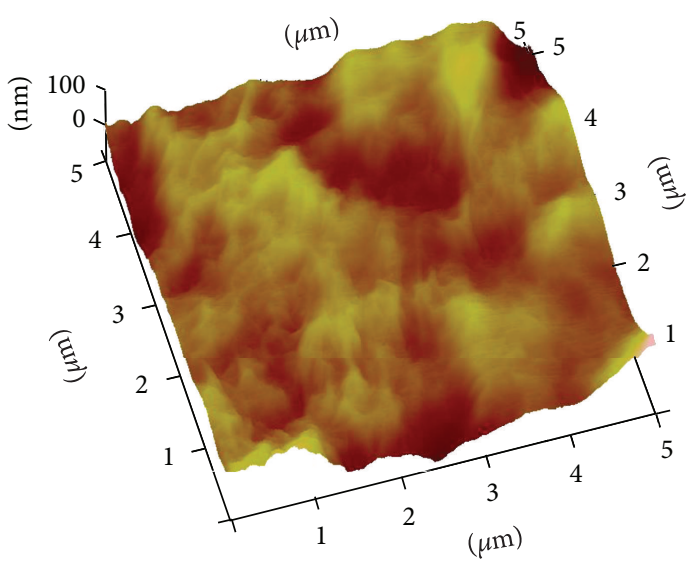

(a)

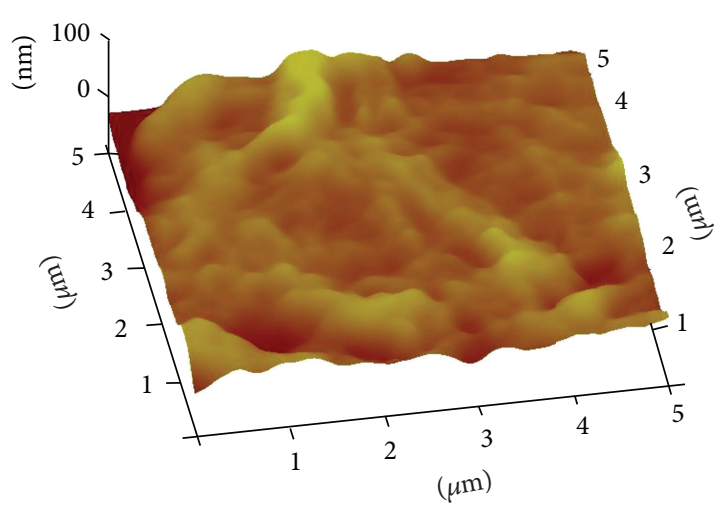

(b)

FIGURE 5: AFM topography of (a) graphene oxide and (b) reduced graphene oxide in $3 \mathrm{D}$.

reduced to graphene. The absence of the $2 \mathrm{D}$ band around $2726 \mathrm{~cm}^{-1}$ after oxidation indicates that all graphite layers have been oxidized. Two peaks around $1500 \mathrm{~cm}^{-1}$ (D and $\mathrm{G}$ band) are essentially identical to the characteristic peaks of graphene oxide. Therefore, oxidized expandable graphite (EG) is the same material as graphene oxide $(\mathrm{GO})$ made from graphite.

\section{Conclusion}

In conclusion, we have demonstrated that commercial flake graphite powder can be oxidized into graphene oxide and reduced in graphene through exfoliation and intercalation processes in polar aprotic solvents as evidenced by chemical reduction method. The characterization of graphene indicates that the chemical reduction method by hydrazine hydrate treatment produces small yield. This is a big challenge; however, it results in unsaturated carbon atoms which can be used in variety of applications such as gas sensing since graphene properties can be significantly affected by substances like hydrogen peroxide $\left(\mathrm{H}_{2} \mathrm{O}_{2}\right)$. This oxidation and reduction has been proved by a number of spectroscopic, vibrational, and optical techniques which were undertaken during this study. 


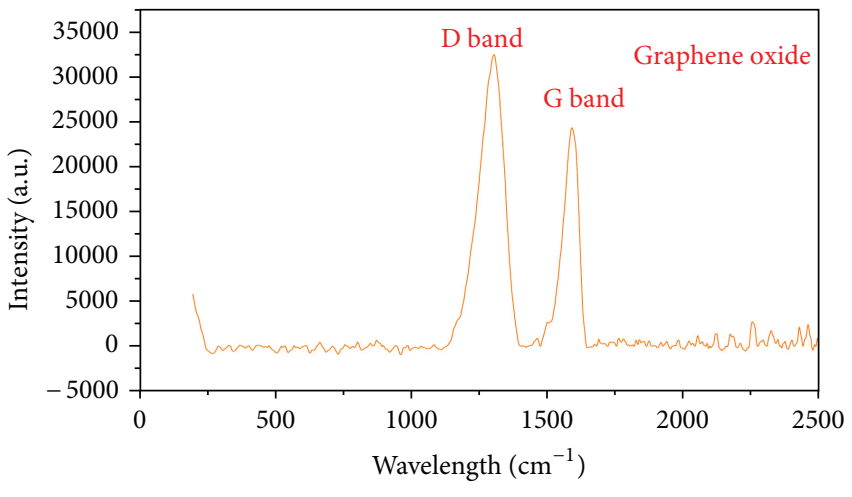

(a)

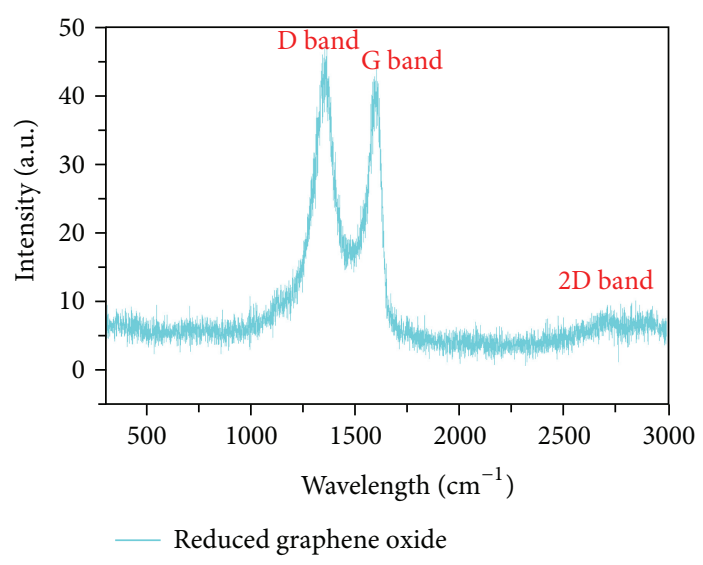

(b)

FiguRE 6: Raman spectra of (a) graphene oxide and (b) reduced graphene oxide.

\section{Acknowledgments}

This work was supported by the Faculty of Applied and Computer Science Research and Publications Committee of Vaal University of Technology, Vanderbijlpark, iThemba Laboratories, Cape Town, South Africa, and Botswana College of Agriculture, Gaborone, Botswana.

\section{References}

[1] L. Feng, Y. Chen, J. Ren, and X. Qu, "A graphene functionalized electrochemical aptasensor for selective label-free detection of cancer cells," Biomaterials, vol. 32, no. 11, pp. 2930-2937, 2011.

[2] A. K. Gein, "Extracting potentials from spectra," Science, vol. 324, pp. 1526-1534, 2009.

[3] P. V. Kamat, "Graphene-based nanoassemblies for energy conversion," The Journal of Physical Chemistry Letters, vol. 2, pp. 242-251, 2011.

[4] C. N. R. Rao, A. K. Sood, R. Voggu, and K. S. Subrahmanyam, "Some novel attributes of graphene," Journal of Physical Chemistry Letters, vol. 1, no. 2, pp. 572-580, 2010.

[5] M. H. Liang, B. Luo, and L. J. Zhi, "Application of graphene and graphene-based materials in clean energy-related devices," International Journal of Energy Research, vol. 33, no. 13, pp. 1161-1170, 2009.

[6] P. V. Kamat, "Graphene-based nanoarchitectures. Anchoring semiconductor and metal nanoparticles on a two-dimensional carbon support," Journal of Physical Chemistry Letters, vol. 1, pp. 520-527, 2010.

[7] W. S. Hummers and R. E. Offeman, "Preparation of graphitic oxide," Journal of the American Chemical Society, vol. 80, no. 6 , pp. 1339-1439, 1958.

[8] B. T. Kelly, Physics of Graphite, Applied Science, London, UK, 1981.

[9] N. A. Kotov, "Materials science: carbon sheet solutions," Nature, vol. 442, no. 7100, pp. 254-255, 2006.

[10] S. Stankovich, D. A. Dikin, R. D. Piner et al., "Synthesis of graphene-based nanosheets via chemical reduction of exfoliated graphite oxide," Carbon, vol. 45, no. 7, pp. 1558-1565, 2007.

[11] D. D. L. Chung, "Exfoliation of graphite," Journal of Materials Science, vol. 22, no. 12, pp. 4190-4198, 1987.
[12] L. H. Viculis, J. J. Mack, and R. B. Kaner, "A chemical route to carbon nanoscrolls," Science, vol. 299, no. 5611, p. 1361, 2003.

[13] S. Park and R. S. Ruoff, "Chemical methods for the production of graphenes," Nature Nanotechnology, vol. 4, no. 4, pp. 217-224, 2009.

[14] R. Muszynski, B. Seger, and P. V. Kamat, "Decorating graphene sheets with gold nanoparticles," Journal of Physical Chemistry C, vol. 112, no. 14, pp. 5263-5266, 2008.

[15] B. Seger and P. V. Kamat, "Electrocatalytically active grapheneplatinum nanocomposites. Role of 2-D carbon support in pem fuel cells," Journal of Physical Chemistry C, vol. 113, no. 19, pp. 7990-7995, 2009.

[16] K. Vinodgopal, B. Neppolian, I. V. Lightcap, F. Grieser, M. Ashokkumar, and P. V. Kamat, "Sonolytic design of graphene$\mathrm{Au}$ nanocomposites. Simultaneous and sequential reduction of graphene oxide and Au(III)," Journal of Physical Chemistry Letters, vol. 1, no. 13, pp. 1987-1993, 2010.

[17] H. M. A. Hassan, V. Abdelsayed, A. E. R. S. Khder et al., "Microwave synthesis of graphene sheets supporting metal nanocrystals in aqueous and organic media," Journal of Materials Chemistry, vol. 19, no. 23, pp. 3832-3837, 2009.

[18] A. F. Zedan, S. Sappal, S. Moussa, and M. S. El-Shall, "Ligand-controlled microwave synthesis of cubic and hexagonal cdse nanocrystals supported on graphene. Photoluminescence quenching by graphene," Journal of Physical Chemistry C, vol. 114, no. 47, pp. 19920-19927, 2010.

[19] V. Abdelsayed, S. Moussa, H. M. Hassan, H. S. Aluri, M. M. Collinson, and M. S. El-Shall, "Photothermal deoxygenation of graphite oxide with laser excitation in solution and grapheneaided increase in water temperature," Journal of Physical Chemistry Letters, vol. 1, no. 19, pp. 2804-2809, 2010.

[20] D. A. Sokolov, K. R. Shepperd, and T. M. Orlando, "Formation of graphene features from direct laser-induced reduction of graphite oxide," Journal of Physical Chemistry Letters, vol. 1, no. 18, pp. 2633-2636, 2010.

[21] Y. H. Ng, I. V. Lightcap, K. Goodwin, M. Matsumura, and P. V. Kamat, "To what extent do graphene scaffolds improve the photovoltaic and photocatalytic response of $\mathrm{TiO}_{2}$ nanostructured films?" Journal of Physical Chemistry Letters, vol. 1, no. 15, pp. 2222-2227, 2010.

[22] Y. H. Ng, A. Iwase, A. Kudo, and R. Amal, "Reducing graphene oxide on a visible-light $\mathrm{BiVO}_{4}$ photocatalyst for 
an enhanced photoelectrochemical water splitting," Journal of Physical Chemistry Letters, vol. 1, no. 17, pp. 2607-2612, 2010.

[23] G. Williams, B. Seger, and P. V. Kamt, " $\mathrm{TiO}_{2}$-graphene nanocomposites. UV-assisted photocatalytic reduction of graphene oxide," ACS Nano, vol. 2, no. 7, pp. 1487-1491, 2008.

[24] G. Williams and P. V. Kamat, "Graphene-semiconductor nanocomposites: excited-state interactions between $\mathrm{ZnO}$ nanoparticles and graphene oxide," Langmuir, vol. 25, no. 24, pp. 13869-13873, 2009.

[25] G. K. Ramesha and S. Sampath, "Electrochemical reduction of oriented Graphene oxide films: an in situ Raman spectroelectrochemical study," Journal of Physical Chemistry C, vol. 113, no. 19, pp. 7985-7989, 2009.

[26] A. Kongkanand, K. Vinodgopal, S. Kuwabata, and P. V. Kamat, "Highly dispersed Pt catalysts on single-walled carbon nanotubes and their role in methanol oxidation," Journal of Physical Chemistry B, vol. 110, no. 33, pp. 16185-16188, 2006.

[27] R. S. Pantelic, J. C. Meyer, U. Kaiser, W. Baumeister, and J. M. Plitzko, "Graphene oxide: a substrate for optimizing preparations of frozen-hydrated samples," Journal of Structural Biology, vol. 170, no. 1, pp. 152-156, 2010.

[28] Z. J. Fang, K. Wang, T. Wei, J. Yan, L. Song, and B. Shao, “An environmentally friendly and efficient route for the reduction of graphene oxide by aluminum powder," Carbon, vol. 48 , no. 5 , pp. 1686-1689, 2010.

[29] T. N. Lambert, C. A. Chavez, B. Hernandez-Sanchez et al., "Synthesis and characterization of titania-graphene nanocomposites," Journal of Physical Chemistry C, vol. 113, no. 46, pp. 19812-19823, 2009.

[30] C. Hou, Q. Zhang, M. Zhn, Y. Li, and H. Wang, "Onestep synthesis of magnetically-functionalized reduced graphite sheets and their use in hydrogels," Carbon, vol. 49, pp. 47-53, 2011.

[31] G. I. Titelman, V. Gelman, S. Bron, R. L. Khalfin, Y. Cohen, and H. Bianco-Peled, "Characteristics and microstructure of aqueous colloidal dispersions of graphite oxide," Carbon, vol. 43, no. 3, pp. 641-649, 2005.

[32] T. Szabo, E. Tombacz, E. Illes, and I. Dekany, "Enhanced acidity and $\mathrm{pH}$-dependent surface charge characterization of successively oxidized graphite oxides," Carbon, vol. 44, no. 3 , pp. 537-545, 2006.

[33] S. Stankovich, R. D. Piner, X. Chen, N. Wu, S. T. Nguyen, and R. S. Ruoff, "Stable aqueous dispersions of graphitic nanoplatelets via the reduction of exfoliated graphite oxide in the presence of poly(sodium 4-styrenesulfonate)," Journal of Materials Chemistry, vol. 16, no. 2, pp. 155-158, 2006.

[34] S. Stankovich, R. D. Piner, S. T. Nguyen, and R. S. Ruoff, "Synthesis and exfoliation of isocyanate-treated graphene oxide nanoplatelets," Carbon, vol. 44, no. 15, pp. 3342-3347, 2006. 

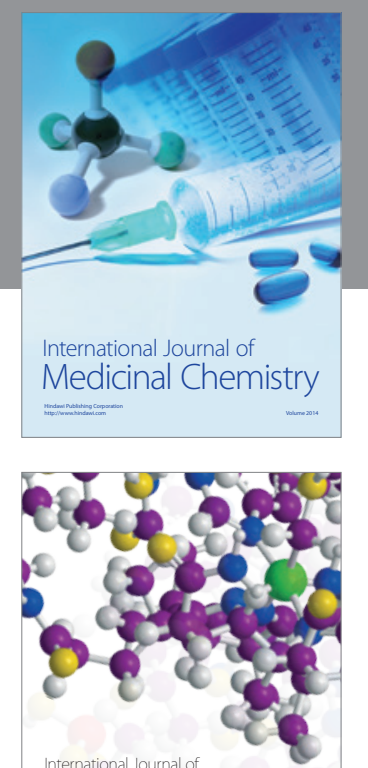

\section{Carbohydrate} Chemistry

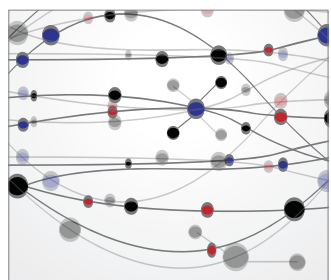

The Scientific World Journal
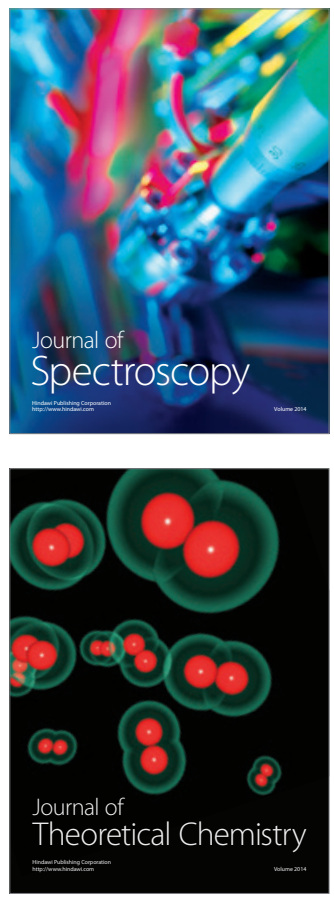
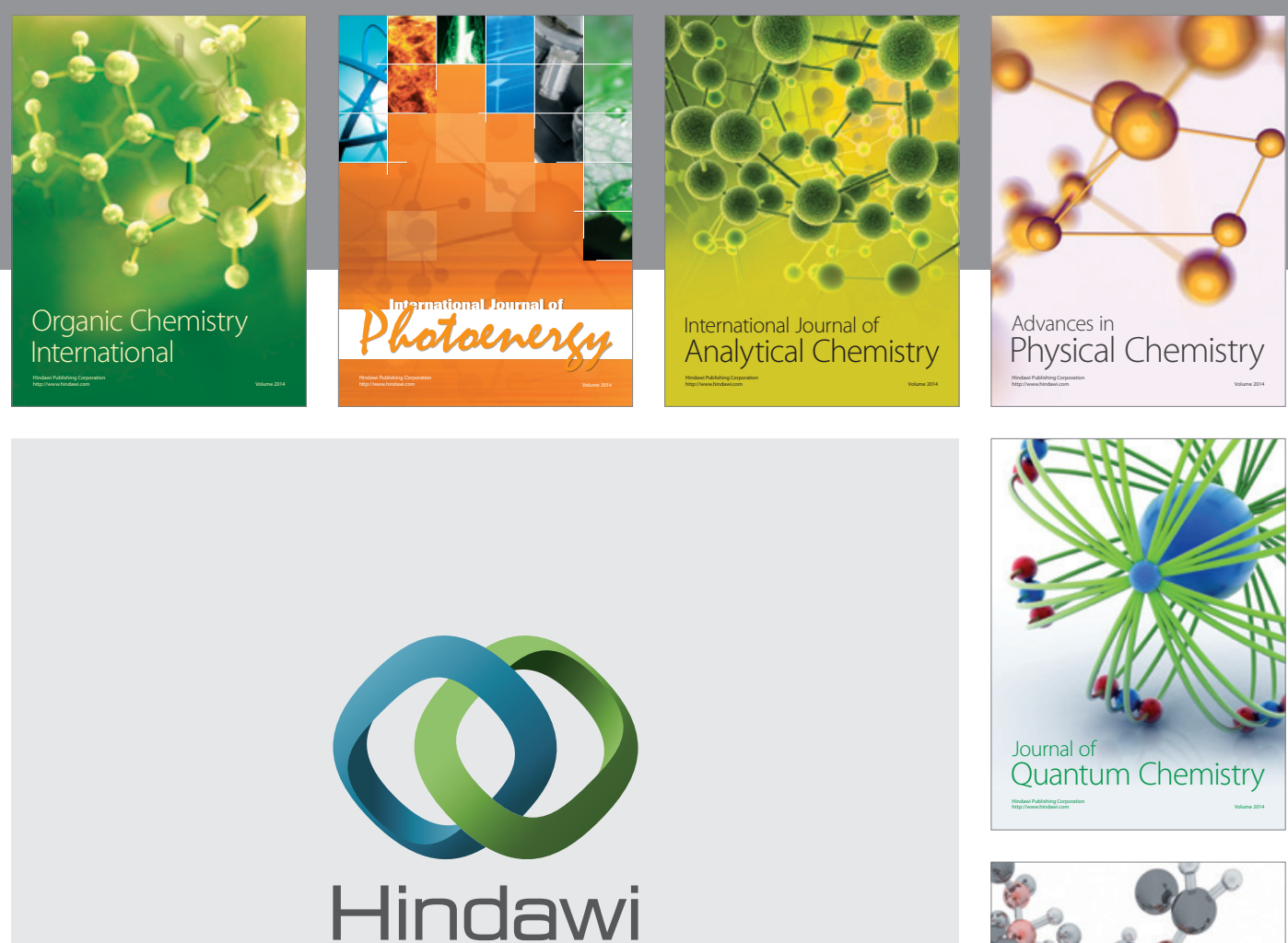

Submit your manuscripts at

http://www.hindawi.com

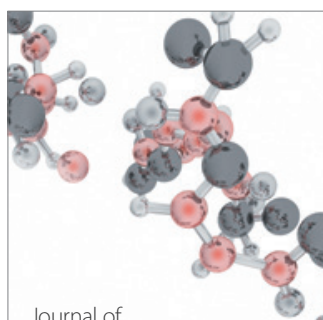

Analytical Methods

in Chemistry

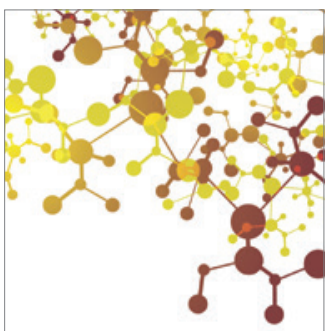

Journal of

Applied Chemistry

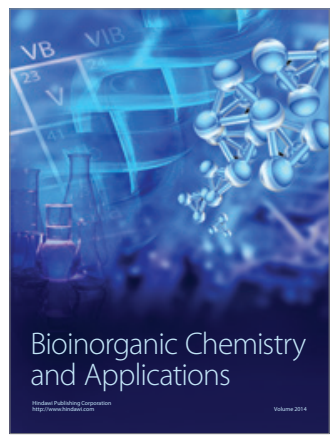

Inorganic Chemistry
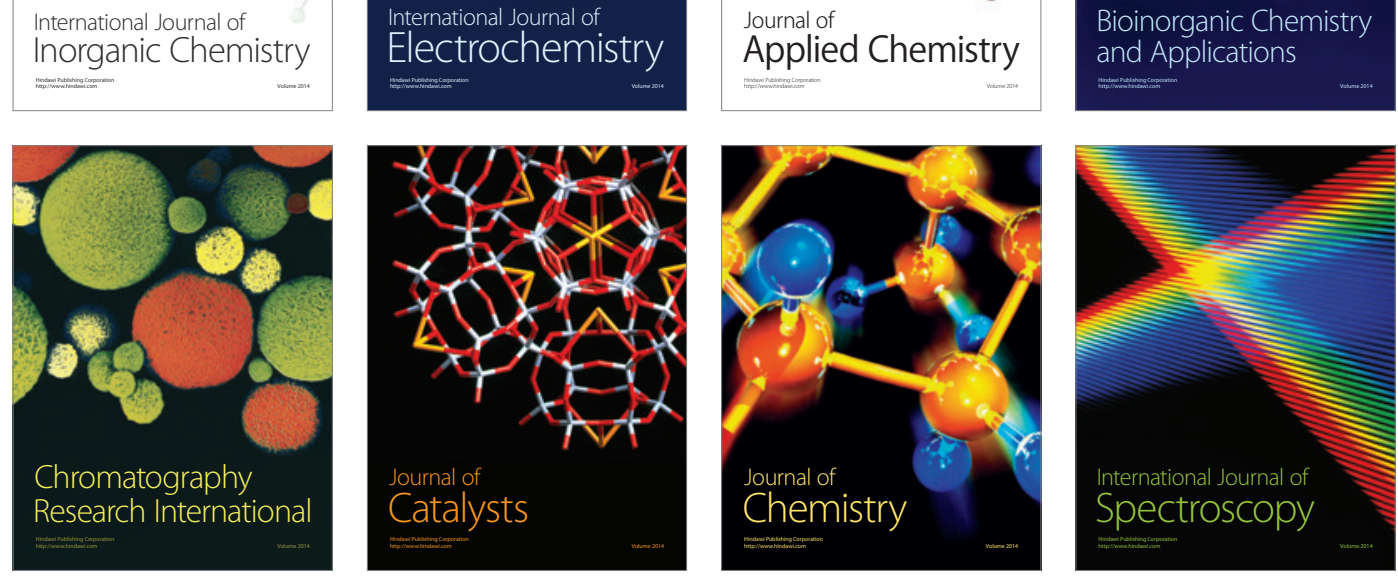